\title{
Promotion of Cobalt Fischer-Tropsch Catalysts with Noble Metals: a Review
}

\author{
F. Diehl' and A.Y. Khodakov² \\ 1 Institut français du pétrole, IFP-Lyon, Catalysis and Separation Division, BP 3, 69360 Solaize Cedex - France \\ 2 Unité de Catalyse et de Chimie du Solide, UMR 8181 CNRS, Bât. C3, USTL-ENSCL-EC Lille, Cite Scientifique, 59655 Villeneuve d'Ascq - France \\ e-mail: fabrice.diehl@ifp.fr - andrei.khodakov@univ-lille1.fr
}

Résumé- Promotion par les métaux nobles de catalyseurs Fischer-Tropsch à base de cobalt : une revue - La synthèse Fischer-Tropsch est une part essentielle du procédé XTL (X-To-Liquids, avec X = Gaz, Biomasse ou Charbon) qui convertit du gaz de synthèse en hydrocarbures pour carburants propres. Les catalyseurs à base de cobalt supportés sur des oxydes inorganiques constituent le meilleur compromis pour la production de paraffines à longues chaînes carbonées et de cires. L'efficacité du procédé FischerTropsch dépend très fortement de la performance du catalyseur à base de cobalt. La promotion de ce catalyseur par des métaux précieux peut très fortement améliorer ses performances. Cet article fait la revue des différents effets des métaux nobles sur la structure et la performance de catalyseurs à base de cobalt. Les impacts sur le coût et l'activité des catalyseurs apparaissent comme des éléments incontournables dans le design de catalyseurs performants pour la synthèse Fischer-Tropsch.

\begin{abstract}
Promotion of Cobalt Fischer-Tropsch Catalysts with Noble Metals: a Review - FischerTropsch synthesis is a major part of XTL (X-To-Liquids, with X = Gas, Biomass or Coal) technologies, which converts syngas into clean hydrocarbon fuels. Cobalt catalysts supported by inorganic oxides appear to be a reasonable compromise for the synthesis of long-chain paraffins and waxes. The efficiency of Fischer-Tropsch technology strongly depends on the performance of cobalt catalysts. Promotion of cobalt catalysts with noble metals results in a significant increase in Fischer-Tropsch catalytic activity. This paper reviews different effects on the structure and catalytic performance of cobalt supported Fischer-Tropsch catalysts which arise from the promotion with noble metals. Both catalytic performance and catalyst cost seem to be major criteria in the design of efficient cobalt Fischer-Tropsch catalysts.
\end{abstract}




\section{COBALT CATALYSTS FOR FISCHER-TROPSCH SYNTHESIS}

\subsection{Fischer-Tropsch Synthesis}

Fischer-Tropsch (FT) synthesis produces hydrocarbons from carbon monoxide and hydrogen. It allows utilization of abundant reserves of natural gas, coal and biomass. The FT reaction was discovered in 1920ies by Hans Fischer and Franz Tropsch on iron and cobalt catalysts. Since then it has been shown that most of metals of the VIII group of the Periodic Table exhibit noticeable activity in hydrocarbon synthesis from carbon monoxide and hydrogen. Among all these metals however, only cobalt and iron catalysts have found industrial application. Cobalt catalysts [1] seem to be a reasonable compromise for the synthesis of middle distillates and waxes. They are typically used in the low-temperature FT synthesis [2,3], which proceeds either in a multi-tubular fixed bed or in a slurry bubble column reactors at $493-513 \mathrm{~K}$ and at total syngas pressure of 20-30 bars. The low-temperature FT synthesis involves syngas with a high $\mathrm{H}_{2} / \mathrm{CO}$ ratio $(\sim 2)$, which is generated from natural gas by vaporeforming, autothermal reforming or partial oxidation. The synergy of catalyst, catalytic reactor and reaction conditions seems to be the key issue [1] in obtaining high and stable yields of clean hydrocarbon fuels and waxes.

The chemical composition of conventional patented cobalt FT catalysts is shown in Figure 1. The cobalt catalysts $[1,4]$ involved in the low-temperature FT synthesis are usually supported on inorganic oxides with high surface area such as alumina, silica or titania. The cobalt FT catalysts typically contain between 15 and $30 \%$ weight of cobalt. Often these catalysts also contain small amounts of the metal-promoter (typically noble metals, $0.05-0.1 \%$ weight) and oxide promoter (zirconia, lantania, cerium oxide, 1-10\%). Numerous studies have shown that introduction of even small amounts of noble metals $(\mathrm{Ru}, \mathrm{Rh}, \mathrm{Pt}$ and Pd) has a strong impact on the properties of cobalt FT catalysts. The paper reviews the effects of promotion with noble metals on the structure and catalytic performance of cobalt supported catalysts in FT synthesis.

\subsection{Requirements to the Efficient Cobalt Catalysts for Low Temperature Fischer-Tropsch Synthesis}

Before discussing the promotion with noble metals, let us briefly examine the specific requirements to the structure of efficient cobalt catalysts for low temperature FT synthesis. It is known that FT synthesis proceeds on the surface of cobalt metal particles which are dispersed on the catalytic support. There is currently a consensus in the literature that for relatively large cobalt particles $(d>8 \mathrm{~nm})$, FT reaction rate is proportional to the overall number of cobalt

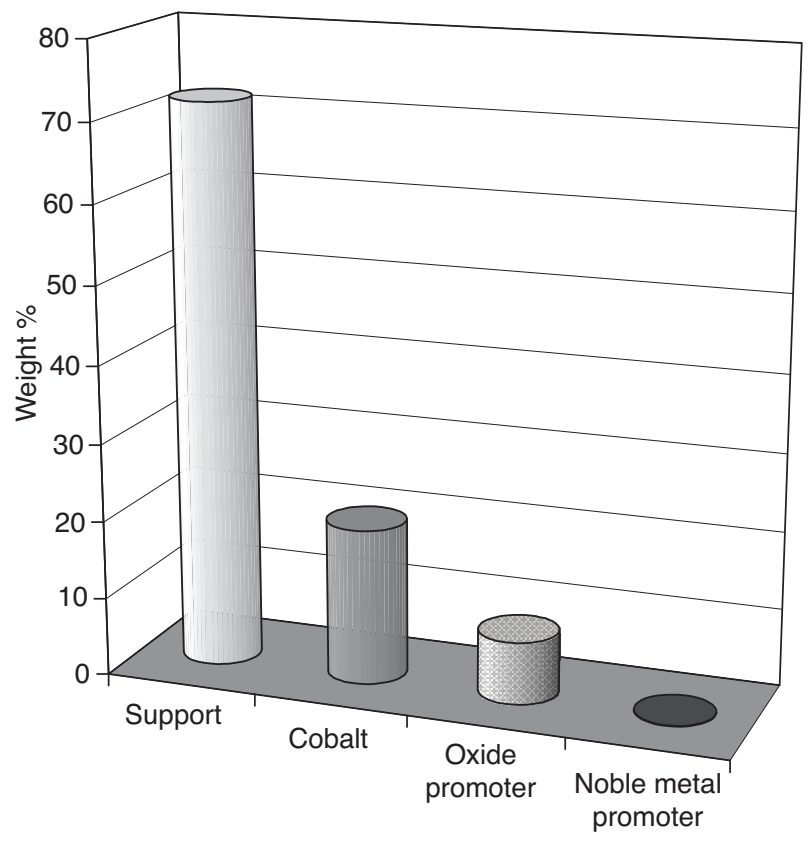

Figure 1

Typical composition of conventional patented cobalt FischerTropsch catalysts.

surface sites. The number of cobalt surface sites in metal supported catalysts depends on particle size, particle morphology, extent of metal reduction and particle stability. Optimization of cobalt particle size and cobalt reducibility seems to be the most obvious goals in the design of any efficient cobalt catalysts for FT synthesis. In fixed bed multi-tubular reactor, the reaction rate and in particular the selectivity can be greatly affected by intraparticle diffusion in larger grains of cobalt catalyst. In this case, the uniform distribution of cobalt metal sites through the catalyst grain does not necessarily leads to the highest hydrocarbon selectivity and optimal yields of higher hydrocarbons. Iglesia et al. [5, 6] has shown that egg-shell catalysts with a tunable thickness of cobalt active phase in subsurface layer produce lesser amounts of methane and can be very efficient in FT synthesis. Thus, a controlled repartition of active sites in a catalyst grain seems to be an essential parameter in the catalyst preparation.

It has been shown that specific apparent activity of cobalt surface sites in FT synthesis is much smaller with smaller cobalt supported particles than with larger ones. Using carbon nanofibers as catalytic support, de Jong et al. [7] have shown that FT turnover frequencies were much lower for cobalt metal particles smaller than 6-8 $\mathrm{nm}$. Decrease in cobalt particle size to 6-8 $\mathrm{nm}$ also results in higher methane selectivity and higher yields of olefinic 
products. The reasons [1] responsible of lower specific activity of smaller cobalt particles could be (i) catalyst deactivation at FT reaction conditions (cobalt oxidation, coking, sintering, formation of mixed cobalt-support compounds, catalyst attrition...) which can occur more rapidly with smaller cobalt particles and (ii) different electronic structure of smaller and larger cobalt particles which would affect intrinsic activity of cobalt metal sites. This suggests that, in efficient cobalt supported FT catalysts, cobalt metal particle sizes should be larger than 6-8 $\mathrm{nm}$.

In addition to the high density of cobalt surface sites and an optimal cobalt oxide particle size ( $>8 \mathrm{~nm}$ ), efficient cobalt catalysts should not contain significant fractions of cobalt support mixed compounds such as cobalt silicate or cobalt aluminate in the case of silica or alumina supported FT cataysts. These compounds are hardly reducible; they do not produce any active sites for FT synthesis and so are responsible for a lower overall catalytic activity.

The issue of catalyst stability is also very important in the design of cobalt supported FT catalysts. High exothermicity of the FT reaction, poor temperature control, impurities in the feed, presence of water, carbon dioxide, heavier hydrocarbons and organic acids in the reaction products [8], catalyst attrition can result in the alteration of the catalyst structure and affect the catalytic performance. These alterations and, in particular, production of very fine particles from catalyst attrition are usually more significant at higher carbon monoxide conversions. The technical difficulties due to the higher-than-expected catalyst attrition in FT process in slurry bubble column reactor have been recently reported by Sasol at the Oryx GTL plant in Qatar [9]. Sasol also claimed very recently to have substantially reduced the level of fine materials which have choked up the plant's filters.

Finally, conducting FT synthesis in industrial reactors requires significant amounts of catalysts; the feed velocities at FT synthesis rarely exceed several thousands $\mathrm{h}^{-1}$. Thus, the catalyst cost should be minimized by avoiding expensive components for catalyst preparation and simplifying catalyst pretreatment and activation procedures.

Thus, the analysis of the literature suggests that, to be efficient in FT synthesis, cobalt catalysts should contain:

- high density of cobalt surface metal sites;

- desirable distribution of cobalt surface sites in a catalyst grain (in particular in fixed bed reactor);

- cobalt metal particles larger than 6-8 nm;

- low fraction of barely reducible cobalt compounds (cobalt silicate, cobalt aluminate, etc.);

- the cobalt metal surface sites and catalyst structure should be stable at FT reaction conditions;

- the cost of cobalt catalysts should be reduced.

\section{INFLUENCE OF NOBLE METALS (Pt, Pd, Ru AND Re) ON THE STRUCTURE AND CATALYTIC PERFORMANCE OF COBALT FISCHER-TROPSCH CATALYSTS}

Cobalt-based catalysts promoted with noble metals are typically prepared via co-impregnation of porous supports with an aqueous solution of a cobalt salt and noble metal precursors such as perrhenic acid, ruthenium nitrosyl nitrate, tetraammineplatinum (II) nitrate, etc. Use of noble metal chlorides $\left(\mathrm{RuCl}_{3}\right.$ or $\left.\mathrm{H}_{2} \mathrm{PtCl}_{6}\right)$ for co-impregnation is generally not recommended because they can modify the catalyst acidity and could favor olefin hydrocracking and isomerization. Moreover, halides are generally considered to be poisons for metallic cobalt atoms. Besides the modification of the catalytic performance in FT synthesis, noble metal promoters produce a variety of effects on the structure of cobalt catalysts. These modifications could affect cobalt reducibility and/or cobalt dispersion, formation of bimetallic particles, formation of barely reducible cobalt support mixed compounds, decomposition of cobalt precursors and hydrogen activation. Note however that promotion with small amounts of noble metal does not usually have [10] noticeable effect on mechanical properties of cobalt supported catalysts. The effects of promotion with noble metals on catalytic performance and structure of cobalt FT catalysts are reviewed hereafter.

\subsection{Enhancement of Catalytic Performance}

A significant number of publications have addressed the effects of promotion with noble metals on the performance of cobalt catalysts. These effects depend on the catalyst synthesis and test conditions. The most noticeable effect due to the promotion with noble metals is a considerable increase in carbon monoxide conversion rate at steady state conditions. The steady state conditions are usually attained after several hours or several days of FT synthesis. The increase in the rate of carbon monoxide conversion has been usually observed both in fixed bed and slurry reactors (Tables 1-3). The magnitude of enhancement of catalytic performance depends however on the type of catalytic support, noble metal and reaction conditions. Noble metal promotion of alumina-supported cobalt catalysts is known to produce the most active cobalt catalysts for FT synthesis [11]. The effect of promotion with noble metals on FT catalytic performance is usually less pronounced with silica and titania supported catalysts.

Storsæter et al. [12] evaluated the catalytic performance of different cobalt supported catalysts in a fixed bed reactor (Table 1). The monometallic catalysts exhibited hydrocarbon conversion rates between 0.14 and $0.25 \mathrm{~g}_{\mathrm{HC}} /\left(\mathrm{g}_{\text {cat }} \mathrm{h}\right)$. Promotion with Re resulted in a double increase in the rate of hydrocarbon production, while methane and $\mathrm{C} 5+$ selectivities were not much affected. Das et al. [13] observed a significant 
TABLE 1

Catalytic performance of cobalt supported catalysts in fixed bed reactor at $40-45 \%$ CO conversion [12].

Conditions: $\mathrm{H}_{2} / \mathrm{CO}=2.1, P_{\text {tot }}=20$ bar, $T=483 \mathrm{~K}$

\begin{tabular}{|c|c|c|c|c|c|}
\hline \multirow[t]{2}{*}{ Catalyst } & \multirow[t]{2}{*}{ GHSV (ml/g/h) } & \multirow[t]{2}{*}{ CO conversion $(\%)$} & \multirow{2}{*}{$\begin{array}{l}\text { Hydrocarbon formation } \\
\text { rate }(\%)\left(\mathrm{g}_{\mathrm{HC}} /\left(\mathrm{g}_{\text {cat }} \mathrm{h}\right)\right)\end{array}$} & \multicolumn{2}{|c|}{ Selectivity (\%) } \\
\hline & & & & $\mathrm{CH}_{4}$ & $\mathrm{C}_{5+}$ \\
\hline $10 \% \mathrm{Co} / \mathrm{Al}_{2} \mathrm{O}_{3}$ & 2982 & 42.6 & 0.25 & 9.7 & 80.2 \\
\hline $10 \% \mathrm{Co}-0.5 \% \mathrm{Re} / \mathrm{Al}_{2} \mathrm{O}_{3}$ & 5960 & 42.8 & 0.42 & 8.8 & 80.8 \\
\hline $10 \% \mathrm{Co} / \mathrm{SiO}_{2}$ & 3060 & 40.4 & 0.24 & 9.1 & 81.7 \\
\hline $10 \% \mathrm{Co}-0.5 \% \mathrm{Re} / \mathrm{SiO}_{2}$ & 4166 & 40.3 & 0.33 & 8.7 & 83.4 \\
\hline $10 \% \mathrm{Co} / \mathrm{TiO}_{2}$ & 1885 & 39.8 & 0.14 & 10.2 & 81.6 \\
\hline $10 \% \mathrm{Co}-0.5 \% \mathrm{Re} / \mathrm{TiO}_{2}$ & 3595 & 42.6 & 0.30 & 8.9 & 84.8 \\
\hline
\end{tabular}

TABLE 2

Trends in initial catalytic activity observed in slurry CSTR reactor (inlet $\mathrm{H}_{2} / \mathrm{CO}=2$ ) [14]

\begin{tabular}{l|c|c|c|c}
\hline Catalyst & $\begin{array}{c}\text { Space } \\
\text { velocity } \\
\left(\mathrm{SL} / \mathrm{g}_{\mathrm{cat}} / \mathrm{h}\right)\end{array}$ & $P($ bar $)$ & $T(\mathrm{~K})$ & $\begin{array}{c}\text { Carbon } \\
\text { monoxide } \\
\text { conversion }(\%)\end{array}$ \\
\hline $15 \% \mathrm{Co} / \mathrm{Al}_{2} \mathrm{O}_{3}$ & 5 & 19.0 & 493 & 22.7 \\
\hline $15 \% \mathrm{Co}-0.5 \% \mathrm{Pt} / \mathrm{Al}_{2} \mathrm{O}_{3}$ & 5 & 19.0 & 493 & 40.2 \\
\hline $10 \% \mathrm{Co} / \mathrm{TiO}_{2}$ & 2 & 24.1 & 503 & 58.4 \\
\hline $10 \% \mathrm{Co}-0.2 \% \mathrm{Ru} / \mathrm{TiO}_{2}$ & 2 & 24.1 & 503 & 77.9 \\
\hline $15 \% \mathrm{Co} / \mathrm{SiO}_{2}$ & 1 & 24.1 & 493 & 64.3 \\
\hline $15 \% \mathrm{Co}-1.9 \% \mathrm{Pt} / \mathrm{SiO}_{2}$ & 1 & 24.1 & 493 & 76.0 \\
\hline
\end{tabular}

increase in FT reaction rate over Re-promoted catalysts in slurry continuous stirred tank reactor (CSTR). Jacobs et al. [14] showed (Table 2) that promotion with platinum and ruthenium of alumina, titania and silica supported catalysts considerably increases FT reaction rate in a slurry reactor. For alumina supported, titania supported and silica supported catalysts, carbon monoxide conversion increased respectively from 22.7 to $40.2 \%$, from 58.4 to $77.9 \%$ and from 64.3 to $76.0 \%$.

The increase in FT reaction rate on promotion with noble metals is usually more noticeable when the catalytic tests are conducted at atmospheric pressure. Schanke et al. [15] observed at atmospheric pressure in fixed bed reactor a 3-5 times increase in carbon monoxide hydrogenation rate on Pt-promoted alumina and silica supported catalysts; under 5 bar, the same authors [15] find that a $0.1 \%$ Pt-promoted cobalt alumina supported catalyst is $70 \%$ more active than the non promoted cobalt catalyst. Similarly at atmospheric pressure, Kogelbauer et al. [16] reported a quadruple increase in carbon monoxide hydrogenation rate after promotion of 20 wt. $\% \mathrm{Co} / \mathrm{Al}_{2} \mathrm{O}_{3}$ catalysts with $0.5 \%$ of ruthenium. A more
TABLE 3

Catalytic performance of $\mathrm{Co} / \mathrm{SiO}_{2}$ catalysts for carbon monoxide hydrogenation in slurry CSTR reactor [18]. Conditions: $513 \mathrm{~K}, 10$ bars, $\mathrm{H}_{2} / \mathrm{CO}=2$; W/F $=5 \mathrm{~g}_{\text {cat }} \mathrm{h} / \mathrm{mol}^{-1}$ )

\begin{tabular}{|c|c|c|c|c|c|}
\hline Catalyst & $\begin{array}{c}\text { CO conv. } \\
(\%)\end{array}$ & $\begin{array}{c}\mathrm{CH}_{4} \\
\operatorname{sel}(\%)\end{array}$ & $\begin{array}{c}\mathrm{CO}_{2} \\
\operatorname{sel}(\%)\end{array}$ & alpha & $\begin{array}{c}\text { Cobalt- } \\
\text { time yield } \\
\left(\times 10^{4} \mathrm{~s}^{-1}\right)\end{array}$ \\
\hline $10 \% \mathrm{Co} / \mathrm{SiO}_{2}{ }^{\mathrm{a}}$ & 33.5 & 8.9 & 1.3 & 0.83 & 1.86 \\
\hline $10 \% \mathrm{Co}-0.2 \% \mathrm{Ru} / \mathrm{SiO}_{2}^{\mathrm{a}}$ & 72.3 & 8.8 & 3.3 & 0.76 & 4.02 \\
\hline $10 \% \mathrm{Co}-0.2 \% \mathrm{Pt} / \mathrm{SiO}_{2}{ }^{\mathrm{a}}$ & 49.5 & 13.8 & 9.5 & 0.75 & 2.75 \\
\hline $10 \% \mathrm{Co}-0.2 \% \mathrm{Pd} / \mathrm{SiO}_{2}{ }^{\mathrm{a}}$ & 57.6 & 17.8 & 4.8 & 0.75 & 3.22 \\
\hline $10 \% \mathrm{Co}-0.2 \% \mathrm{Ru} / \mathrm{SiO}_{2}{ }^{\mathrm{b}}$ & 56.7 & 6.3 & 2.2 & 0.88 & 3.15 \\
\hline $10 \% \mathrm{Co} / \mathrm{SiO}_{2}{ }^{\mathrm{c}}$ & 29.8 & 6.6 & 1.6 & 0.86 & 1.66 \\
\hline
\end{tabular}

than 8 times increase in FT reaction rate at atmospheric pressure was observed in our recent report [17] after promotion of $10 \mathrm{wt} . \% \mathrm{Co} / \mathrm{Al}_{2} \mathrm{O}_{3}$ catalysts with $0.1 \%$ of platinum.

The positive effect of noble metals on hydrocarbon selectivity is usually less claimed in the literature. It is generally reported that cobalt catalysts promoted with the noble metals which have high hydrogenation activity such as $\mathrm{Pt}$ and $\mathrm{Pd}$, exhibit higher methane selectivity, smaller chain growth probability and lower selectivity to higher hydrocarbons than their cobalt monometallic counterparts. The drop of chain growth probability and selectivity to higher hydrocarbons is more pronounced at higher contents of noble metals (>0.1 wt.\%). The modification of hydrocarbon selectivity is less noticeable over the cobalt FT catalysts promoted with Ru and Re. Table 3 displays catalytic data obtained by Tsubaki et al. [18] in slurry autoclave reactor for cobalt silica-supported catalysts promoted with $\mathrm{Ru}, \mathrm{Pt}$ and $\mathrm{Pd}$. At carbon monoxide conversions between 49 and 60\%, higher selectivity to methane and carbon dioxide was observed on Pt and 
Pd-promoted catalysts relative to the catalyst promoted with $\mathrm{Ru}$. No significant increase in methane and $\mathrm{CO}_{2}$ selectivity's was observed on Ru-promoted catalysts even at high carbon monoxide conversions ( $>70 \%$ ).

Thus, promotion of cobalt catalysts with noble metals usually results in a considerable increase in overall FT reaction rate which is accompanied by a much smaller effect of the promotion on hydrocarbon selectivity. Higher promoter content can favor methanation, affect chain growth probability and lead to a much lower the selectivity to higher hydrocarbons. Note that these phenomena represent a general trend observed in the literature about FT catalysts. It should be emphasized however that the catalytic performance of cobalt FT catalysts is very sensitive to catalyst preparation and conditions of catalyst evaluation. Some additional effects of noble metals on the catalytic performance of cobalt FT catalysts can be observed as a function of catalyst preparation, activation and testing conditions.

\subsection{Cobalt Reducibility}

It has been largely shown [19-26] that promotion of cobalt FT catalysts with noble metals enhances cobalt reducibility. The improvements in cobalt reducibility may occur without any affect on cobalt dispersion as observed by Davis for $\mathrm{CoRe} / \mathrm{Al}_{2} \mathrm{O}_{3}$ catalysts [13]. While the improvement in cobalt reducibility has been observed with several noble metals (Pt, $\mathrm{Ru}, \mathrm{Pd}, \mathrm{Ir}, \mathrm{Re}$ ), platinum, rhenium and ruthenium seems to be the most efficient cobalt reducibility promoters $[16,18$, 27-29]. The enhancement in cobalt reducibility was observed with a large number of catalytic supports $\left(\mathrm{Al}_{2} \mathrm{O}_{3}\right.$, $\mathrm{SiO}_{2}, \mathrm{TiO}_{2}, \mathrm{ZrO}_{2}$, etc.). The effect of promotion with noble metals on cobalt reducibility is particularly pronounced with alumina supported catalysts. It was shown using XPS [30] that in the case of monometallic cobalt alumina-supported catalysts reduction with hydrogen, cobalt was almost exclusively in oxidized $(\mathrm{CoO})$ form, while promotion with $\mathrm{Pt}$ resulted in a considerable fraction of metallic cobalt. Note that even very small amounts of noble metals (0.05-0.1 wt.\%) are often sufficient for dramatic enhancement in cobalt reducibility.

In the oxidic form of cobalt catalysts, $\mathrm{Co}_{3} \mathrm{O}_{4}$ is usually the dominant cobalt phase. Several previous reports [31-35] suggest that reduction of $\mathrm{Co}_{3} \mathrm{O}_{4}$ to metallic cobalt may proceed via intermediate formation of $\mathrm{CoO}$ :

$$
\mathrm{Co}_{3} \mathrm{O}_{4} \rightarrow \mathrm{CoO} \rightarrow \mathrm{Co}
$$

Figure 2 shows TPR profiles of monometallic and Ptpromoted cobalt alumina supported catalysts [17]. Promoting with Pt results in a low-temperature shift of the TPR peaks which were schematically attributed to both reduction of $\mathrm{Co}_{3} \mathrm{O}_{4}$ to $\mathrm{CoO}$ at $500-650 \mathrm{~K}$ and to reduction of $\mathrm{CoO}$ to metallic cobalt at 650-973 K. Thus, it has been shown that most of noble metals (Pt, Ru, Pd, Ir) enhance the two cobalt

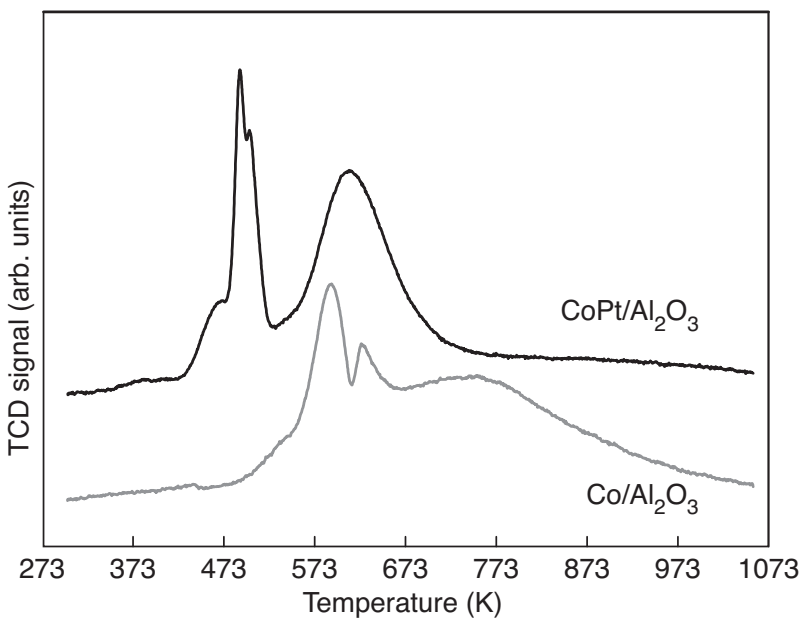

Figure 2

TPR profiles of monometallic and Pt-promoted cobalt alumina supported catalysts (15 wt.\% Co, 0.1 wt.\% Pt, $5 \% \mathrm{H}_{2} / \mathrm{Ar}$, ramp $3 \% \mathrm{~min}$ ).

oxide reduction steps. At the same time, several reports designate that $\mathrm{Re}$ affects only the second reduction step $\mathrm{CoO}$ to Co [14, 26-28]. This was attributed to the reduction of Re occurring at nearly the same temperature as the first reduction step of $\mathrm{Co}_{3} \mathrm{O}_{4}$ to $\mathrm{CoO}$. This suggestion is also consistent with the recently reported results obtained using aberrationcorrected scanning transmission electron microscopy [29]. That report indicates that $\mathrm{Pt}, \mathrm{Ir}, \mathrm{Re}$, or $\mathrm{Ru}$ enhanced the reduction of $\mathrm{CoO}$ to metallic cobalt, while only $\mathrm{Ru}, \mathrm{Pt}$, and $\mathrm{Ir}$ were effective in lowering the temperature for the conversion of $\mathrm{Co}_{3} \mathrm{O}_{4}$ to $\mathrm{CoO}$. The formation of cobalt metal phases from cobalt oxides is an activated process. Our previous report [17] suggests that addition of noble metals results in lower activation energy of the formation of cobalt metal phase. In cobalt alumina supported catalysts, it was found the promotion with $0.1 \% \mathrm{Pt}$ resulted in decrease of the activation energy from 130 to $60 \mathrm{~kJ} / \mathrm{mol}$.

Much easier reduction of cobalt in the presence of noble metals can be due to two different but complementary phenomena. First, it was shown that cobalt reduction [36, 40] proceeds via nucleation/growth autocatalytic model: once metal nuclei have formed on the metal surface, they serve to facilitate the reduction process, most likely via the dissociation and spillover of hydrogen. It is known that noble metals can be easily reduced to the metallic state at much lower temperatures than cobalt oxide. At their metallic state, the noble metals would facilitate dissociation and activation of hydrogen and thus enhance the whole cobalt reduction process. This would decrease the temperature of appearance of cobalt metal phase. The model involving hydrogen spillover and 
autocatalytic reduction has been confirmed by Holmen [36] for $\mathrm{CoRe} / \mathrm{Al}_{2} \mathrm{O}_{3}$ catalysts using TPR experiments. In that work the effect of enhancement of cobalt reducibility similar to that in co-impregnated CoRe catalysts was observed for the intimate mixtures of $\mathrm{Co} / \mathrm{Al}_{2} \mathrm{O}_{3}$ and $\mathrm{Re} / \mathrm{Al}_{2} \mathrm{O}_{3}$ catalysts. This suggests that the direct contact between Re and Co is not necessary in order to obtain a promoting effect of the noble metal on catalyst reducibility. The spillover mechanism of enhancement of cobalt reduction is also consistent with non-variance of intrinsic site activity of cobalt catalysts after promotion with noble metals $(\mathrm{Pt}, \mathrm{Re})$ usually observed by SSITKA method [16, 41-43] or calculated by normalizing the overall FT reaction rate by the number of metal sites measured by $\mathrm{H}_{2}$ chemisorption [13].

The second mechanism of influence of noble metal on cobalt reduction involves formation of bimetallic particles of cobalt with noble metals. The formation of bimetallic particles in cobalt catalysts promoted with noble metals is discussed in Section 2.4 of this paper. Because of incorporation of noble metal atoms in cobalt particles, these particles can be reduced at much lower temperatures than monometallic cobalt. In alumina supported Pt-supported catalysts Davis et al. [44] showed that Pt is likely to be situated on the edge of the cobalt metal cluster without forming Pt-Pt bonds. It was suggested that reduction occurs on Pt first, allowing hydrogen to spill over to the cobalt oxide and nucleate cobalt metal sites. Note that nevertheless the spillover mechanism seems to be predominant in the cobalt catalysts promoted with noble metals, since cobalt reduction proceeds much more readily in the presence of noble metal when even no bimetallic cobalt particles have been detected.

\subsection{Cobalt Dispersion}

The presence of noble metal can affect particle size of both cobalt oxide and metallic cobalt. Analysis of the literature data suggests that the promotion with noble metals primarily reduces the sizes of cobalt oxide particles in weakly interacting supports, e.g. silica. The increase in cobalt dispersion in the presence of platinum in silica supported catalysts was observed by Schanke et al. [15]. In that work, the extent of reduction in the monometallic and Pt-promoted cobalt catalysts was close to $90 \%$. The improvement in catalytic activity on promotion with $\mathrm{Pt}$ was attributed to the enhancement in cobalt dispersion. Higher cobalt dispersion was also observed by Tsubaki [18] in Pt and Pd -promoted cobalt silica supported catalysts. Mauldin et al. [25] reported that rhenium promotion increased cobalt oxide dispersion during preparation of $\mathrm{Co} / \mathrm{TiO}_{2}$ supported catalysts. Our previous report [45] also indicates that the presence of noble metals $(\mathrm{Ru}, \mathrm{Re})$ enhances cobalt oxide dispersion in silica supported catalysts. One of the reasons responsible of higher cobalt oxide dispersion in the catalysts promoted with noble metals could be related to a higher concentration of cobalt oxide nucleation and crystallization sites. Higher concentration of crystallization sites at the similar cobalt content would result in larger number of crystallites and consequently in smaller average cobalt oxide particle size and higher cobalt oxide dispersion.

Promotion with noble metals can also affect the sizes of cobalt metal particles in the reduced cobalt catalysts. Increase in the surface area of metallic cobalt was observed [39] after promotion of $20 \% \mathrm{Co} / \mathrm{Al}_{2} \mathrm{O}_{3}$ catalysts with $\mathrm{Pt}$, Ir, $\mathrm{Re}$, or $\mathrm{Ru}$. The effect of promotion with platinum on cobalt dispersion in the reduced catalysts was rather significant [17] with cobalt alumina supported catalysts. In contrast to silica supported counterparts, in alumina supported catalysts, promotion with Pt did not result in a decrease in the sizes of cobalt oxide particles in the calcined catalysts. At the same time, the average size of cobalt metallic particles was smaller in the catalysts promoted with $\mathrm{Pt}$ than in the monometallic counterparts. Preliminary analysis indicated the presence of only single domain ferromagnetic cobalt particles in the catalysts. The field dependence curves obtained for the reduced cobalt monometallic and Pt-promoted catalysts are shown in Figure 3. The coercive force is called the value of magnetic field required to remove the residual magnetism from the material. Smaller coercive force is observed for the Pt-promoted catalyst. Smaller coercive force is indicative [46] of smaller sizes of metal particles. This suggests that the cobalt metal particles are smaller in $\mathrm{CoPt} / \mathrm{Al}_{2} \mathrm{O}_{3}$ than in the monometallic catalysts. It is now admitted $[32,34,35]$ that smaller cobalt oxide particles are more difficult to reduce than larger ones. This seems to be a reason why smaller cobalt oxide particles usually remain in the oxidized state after the pretreatment of monometallic cobalt alumina supported catalysts with hydrogen. Thus, the presence of platinum results

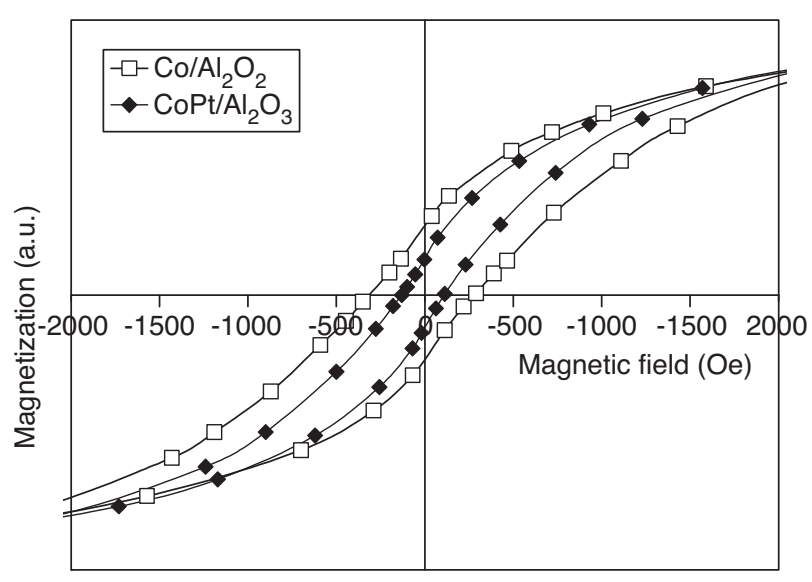

Figure 3

Field dependence curves obtained for the reduced cobalt monometallic and Pt promoted catalysts (15 wt.\% Co, 0.1 wt.\% Pt). 
in the reduction of smaller cobalt particles which are not reducible in the monometallic cobalt catalysts. Similar result was observed by Kogelbauer [16] for cobalt alumina supported catalysts promoted with $\mathrm{Ru}$. It was suggested that a higher number of cobalt metal sites in the promoted catalysts could be attributed to the reduction of smaller cobalt particles in the presence of ruthenium.

\subsection{Formation of Bimetallic Particles}

Promotion of cobalt catalyst with noble metals may lead to the direct interaction between cobalt and promoter and formation of bimetallic cobalt-noble metal particles. The formation of bimetallic particles can occur during oxidative treatments or during reduction of cobalt catalysts. Iglesia $e t$ al. [47] reported the tendency of $\mathrm{Co}$ and $\mathrm{Ru}$ to form mixed oxides during calcination at $573 \mathrm{~K}$. It was also shown that the formation $\mathrm{Co}-\mathrm{Ru}$ bimetallic particles could be enhanced by catalyst oxidative treatments at higher temperatures. The bimetallic oxide particles can be then reduced to the metal particles constituted by atoms of both cobalt and a noble metal.

The presence of atoms of noble metal in the bimetallic particles can affect the electronic properties of metallic particles and thus, the performance of cobalt catalysts for FT synthesis. Carlsson et al. [48] showed that in Co-Pd alumina supported systems, the binding energy of carbon monoxide to both Pd and Co sites was lowered in the presence of the other metal. Formation of bimetallic particles resulted in net polarization of charge or redistribution of d-band states. It has been also shown [49] using a combination of LEED and lowenergy ion-scattering spectroscopy that formation of Co-Pt alloys modifies electronic properties of Pt atoms and carbon monoxide adsorption. Promotion with noble metals could lead to an increase in site reactivity. It was found [24] that the presence of noble metals reduced the temperature of carbon monoxide hydrogenation in TPSR experiments. Formation of bimetallic particles of cobalt and noble metal can also lead on dramatic changes in reaction selectivity. Unusually high selectivity to methanol was observed by Reinikainen [22] for mixed $\mathrm{CoRu} / \mathrm{SiO}_{2}$ catalyses, while almost no methanol was produced on either $\mathrm{Co} / \mathrm{SiO}_{2}$ or $\mathrm{Ru} / \mathrm{SiO}_{2}$ catalysts.

The bimetallic particles can be detected in cobalt catalysts by several characterization techniques. In the bimetallic particles, cobalt is directly bonded to atoms of the promoting noble metal. This bonding can be observed by XANES/EXAFS. The capacity of XANES/EXAFS to detect and identify cobalt monometallic and cobalt bimetallic particles in supported catalysts has been recently reviewed by Bazin and Guczi [50,51]. Because of higher concentration of cobalt than a promoting metal in the catalysts, it is easier to detect the presence of cobalt atoms in the first coordination sphere of the noble metal than the presence of noble metals in the first coordination sphere of cobalt. Figure 4 presents

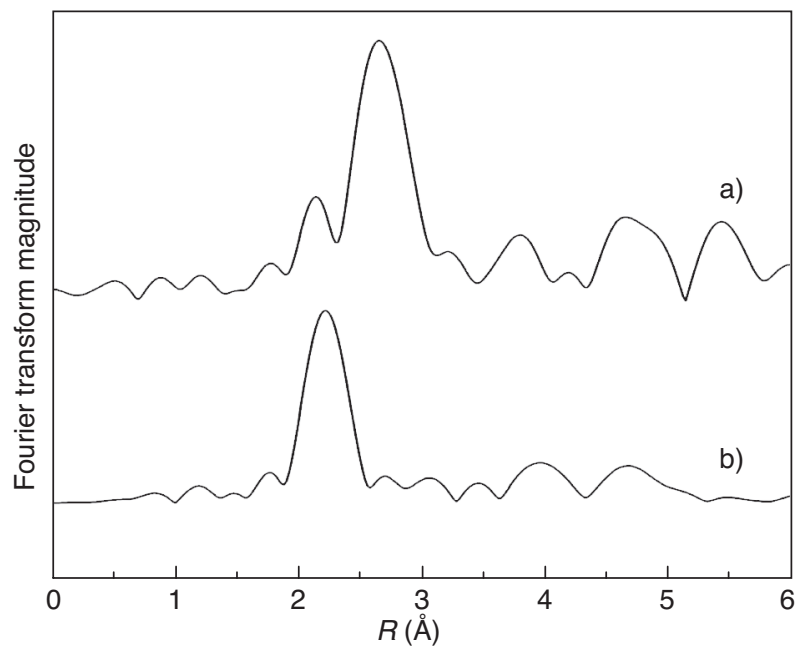

Figure 4

$\mathrm{k}^{3}$-weighed Fourier transform moduli for EXAFS at Pt $\mathrm{L}_{\mathrm{III}}$ absorption edge: $\mathrm{Pt}$ foil a) and $15 \% \mathrm{Co}-1 \% \mathrm{Pt} / \mathrm{Al}_{2} \mathrm{O}_{3}$ catalyst b). The cobalt catalyst was reduced in situ at $673 \mathrm{~K}$ with hydrogen and cooled under hydrogen to room temperature [44].

EXAFS data obtained by Davis et al. [44] at Pt $\mathrm{L}_{\mathrm{III}}$ absorption edge for monometallic cobalt and Pt-promoted alumina supported catalysts. The EXAFS Fourier transform moduli of Pt foil and reduced cobalt catalyst promoted with Pt are different. The peak in the Fourier transform moduli of the cobalt catalyst is situated at $2.1 \AA$. Analysis of the EXAFS implies that the peak at $2.1 \AA$ observed in Fourier transform moduli of the reduced Co catalysts promoted with Pt, could be attributed to Pt-Co coordination in the metallic phase. This is indicative of direct contact of the promoting $\mathrm{Pt}$ atoms with cobalt atoms. The chemical bonds between cobalt and promoting atoms were also found using EXAFS by the groups of Holmen [52] and Davis [38] in the catalysts promoted with Re. Guczi et al. [27, 53] reported the presence of cobaltnoble metal bonds in CoNaY zeolite promoted with platinum. EXAFS and magnetic measurements also uncovered [54] the presence of Co-Pd bimetallic particles in the catalysts supported by niobium oxide.

The presence of bimetallic particles can be also detected using XRD. Pt-Co alloy was observed using XRD at different $\mathrm{Pt} / \mathrm{Co}$ ratio on silica supported catalysts by Dees et al. [55]. Small amounts of cobalt remarkably modified the selectivity of hexane hydrogenation reaction. It was suggested that metal surface of bimetallic Pt/Co particles was probably enriched by cobalt.

Modern electron microscopy in combination with EDS and EELS also allows identification of bimetallic particles in cobalt FT catalysts. Formation of Co-Pt, Co-Ru, Co-Pd bimetallic particles was shown by Tsubaki et al. $[18,56]$ in 
$\mathrm{Co} / \mathrm{SiO}_{2}$ catalysts using EDS spectroscopy with an electron beam width of $0.5 \mathrm{~nm}$. The CoRu particles were particularly enriched in ruthenium while the chemical composition of CoPd and CoPt particles was close to their bulk value. Storsæter et al. [57] also observed using STEM-EDS that rhenium was in close contact with the cobalt in oxidized cobalt catalysts supported by $\mathrm{TiO}_{2}, \mathrm{SiO}_{2}$ and $\gamma-\mathrm{Al}_{2} \mathrm{O}_{3}$. A more considerable enrichment of cobalt particles with $\mathrm{Re}$ was observed in titania and silica supported catalysts. The presence of bimetallic particles in cobalt alumina supported catalysts was detected by Shannon et al. [39] using EELS spectrum imaging. It was found that the Ru clusters were generally associated with cobalt particles, which suggests possible formation of bimetallic cobalt particles. Li et al. [58] showed using HRTEM and EELS, that in Co-Ru alumina supported catalysts, the repartition of cobalt and ruthenium in the bimetallic particles depended on their size. Large metallic particles were principally constituted by cobalt, while a significant fraction of ruthenium was detected in smaller metal particles $(d=1-3 \mathrm{~nm})$. It appears that the presence of $\mathrm{Ru}$ in smaller metal particles enhanced their reduction.

In Co-Pd alumina supported catalysts, the presence of cobalt core-palladium shell bimetallic particles was reported by Nowitzki et al. [59] using a combination of several characterization techniques. The reactivity of these particles strongly depended on extent of coverage of cobalt core by palladium atoms. Cobalt particles with an incomplete $\mathrm{Pd}$ shell were oxidized more readily than the monometallic Co particles. The presence of both cobalt and palladium atoms in the particle shell enhanced cobalt reduction. When the particle shell is essentially constituted by Pd atoms, cobalt oxidation is inhibited because of the limited oxygen diffusion through Pd.

\subsection{Fraction of Barely Reducible Cobalt Support Mixed Compounds}

In addition to cobalt metallic phases, $\mathrm{CoO}$ and $\mathrm{Co}_{3} \mathrm{O}_{4}$ crystalline phases, cobalt catalysts can contain barely reducible cobalt-support mixed compounds (cobalt aluminate, silicate, etc.). These oxides do not yield cobalt metal active phase after reduction, in the usual temperature range used for reducing cobalt catalyst $(T<773 \mathrm{~K})$. They can occur at different steps of catalyst preparation (impregnation, calcination, reduction) or during the FT reaction.

The noble metal promoter can affect formation of cobaltsupport compounds at different stages of catalyst preparation. First, it has been shown [60] that the presence of noble metals influences the crystallization of cobalt oxide phases during decomposition of cobalt precursors. In cobalt catalysts supported by MCM-41 and SBA-15 mesoporous silicas, promotion with $\mathrm{Ru}$ affects repartition of cobalt between easy reducible and barely reducible cobalt phases. High fraction of barely reducible cobalt silicate was found in monometallic

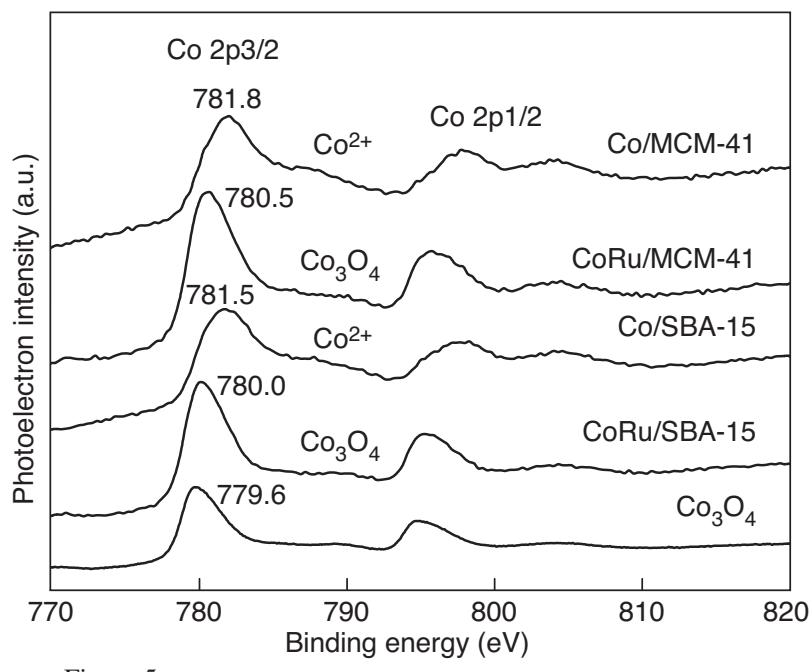

Figure 5

XPS spectra of monometallic and Ru-promoted cobalt catalysts supported by MCM-41 (pore size $3.4 \mathrm{~nm}$ ) and SBA15 silicas (pore size $4.4 \mathrm{~nm}$ ). The catalysts contained $10 \mathrm{wt} . \%$ $\mathrm{Co}$ and in the promoted catalysts $0.3 \mathrm{wt} . \% \mathrm{Ru}$.

cobalt catalysts supported by narrow pore MCM-41 and SBA-15. Figure 5 displays XPS spectra of cobalt silica supported catalysts. For cobalt monometallic catalysts, the binding energies of Co 2p3/2 were 781.5 and $781.8 \mathrm{eV}$, respectively, and a high intensity of the shake-up satellite peaks was observed. These features indicate the presence of $\mathrm{Co}^{2+}$ species in amorphous cobalt silicate species [12, 61, 62] and could be taken as evidence of a strong interaction of the cobalt species with the surface of support. After the addition of ruthenium, the binding energies of Co 2p3/2 were shifted towards lower energies, from $781.8 \mathrm{eV}$ to $780.5 \mathrm{eV}$ and from $781.5 \mathrm{eV}$ to $780.0 \mathrm{eV}$ and the spectrum showed a low intensity of the shake-up satellite peaks, which was typical for $\mathrm{Co}^{2+} / \mathrm{Co}^{3+}$ ions in the $\mathrm{Co}_{3} \mathrm{O}_{4}$ spinel phase $[63,64]$. These results were consistent with XRD data. Thus, promotion with $\mathrm{Ru}$ can result in a decrease in the fraction of cobalt silicate and in an increase in the fraction of reducible cobalt oxide phase detected both by XRD and XPS. Higher fraction of easy reducible cobalt oxide phase leads to higher concentration of cobalt metal sites and higher catalytic activity in FT synthesis [60]. These results are consistent with previous report by Kogelbauer et al. [16]. They showed that promotion with $\mathrm{Ru}$ of $\mathrm{Co} / \mathrm{Al}_{2} \mathrm{O}_{3}$ catalysts inhibited formation of cobalt aluminates which was indicated by disappearance of broad high temperature peaks in TPR profiles of the promoted catalysts.

Secondly, the noble metal promoter can minimize formation of mixed cobalt-support compounds during catalyst reduction and catalytic reaction. It is known that at higher temperatures, unreduced cobalt oxide species can react with 
support yielding cobalt-support mixed oxides. The presence of noble metals during the reduction usually leads to lower temperature of appearance of cobalt metal phase and therefore reduces the fraction of unreduced cobalt oxide and slows down the formation of cobalt support mixed oxides [36]. Finally, the noble metals at the conditions of FT synthesis hinder reaction of cobalt with the support yielding cobalt support mixed compounds. Jongsomjit et al. [65] showed that, at these conditions, promotion with ruthenium delays formation of cobalt oxide species strongly interacting with support and non-reducible cobalt aluminate in cobalt catalysts supported by $\gamma$-alumina.

\subsection{Decomposition of Cobalt Precursors}

Promotion with noble metals could also affect decomposition of cobalt precursor. The effect is particularly pronounced with the cobalt precursors which decompose at temperatures higher than the temperature of decomposition of the precursors of noble metals. Recent report [66] has shown that promotion with ruthenium using ruthenium nitrosyl nitrate could result in a lower temperature of decomposition of cobalt acetate in silica supported catalysts. It is however known that cobalt acetate usually decomposes at $493 \mathrm{~K}$ in the presence of air while ruthenium nitrosyl nitrate decomposes at $423 \mathrm{~K}$. In silica supported CoRu catalysts it was uncovered that decomposition of ruthenium nitrosyl nitrate could initiate decomposition of cobalt acetate. An additional DSC-TGA peak was observed at lower temperatures during cobalt acetate decomposition in the catalysts promoted with ruthenium nitrosyl nitrate (Fig. 6). In the catalysts promoted with ruthenium, cobalt acetate decomposes in a much broader temperature range and at lower temperatures than in monometallic catalysts. Promotion with ruthenium of the catalysts obtained from cobalt acetate increased the concentration of $\mathrm{Co}_{3} \mathrm{O}_{4}$ crystallites and reduced the amount of cobalt silicate.

\subsection{Catalyst Stability}

Iglesia et al. [47] found that promotion with ruthenium decreased irreversible deactivation of cobalt catalysts. Much lower carburization of reduced $\mathrm{Co} / \mathrm{TiO}_{2}$ catalyst was observed in the presence of the noble metals (Fig. 7). Hydrogenolysis of carbonaceous residues catalyzed by ruthenium and reduction of surface oxygen atoms permit consequently regeneration of Co-Ru catalysts in hydrogen at lower temperatures. Better resistance to deactivation leads to higher concentrations of active sites associated with cobalt in the working catalysts at Fischer Tropsch reaction. This finding is consistent with the reports by Guczi et al. [67, 68] who attributed the main promoting effect of Re to the inhibition of deactivation in the catalysts supported by $\mathrm{SiO}_{2}$, $\mathrm{Al}_{2} \mathrm{O}_{3}$ and NaY. In addition to hydrogenolysis of carbonaceous residues, the presence of noble metal can inhibit the formation of cobalt support mixed oxides during FT synthesis. Jongsomjit et al. [65] found that promotion with ruthenium delayed formation of inactive mixed $\mathrm{Co}-\mathrm{Al}$ oxides in the presence of water and thus improved catalyst stability.

Other reports suggest however that promotion with noble metals does not noticeably enhance the catalyst stability.
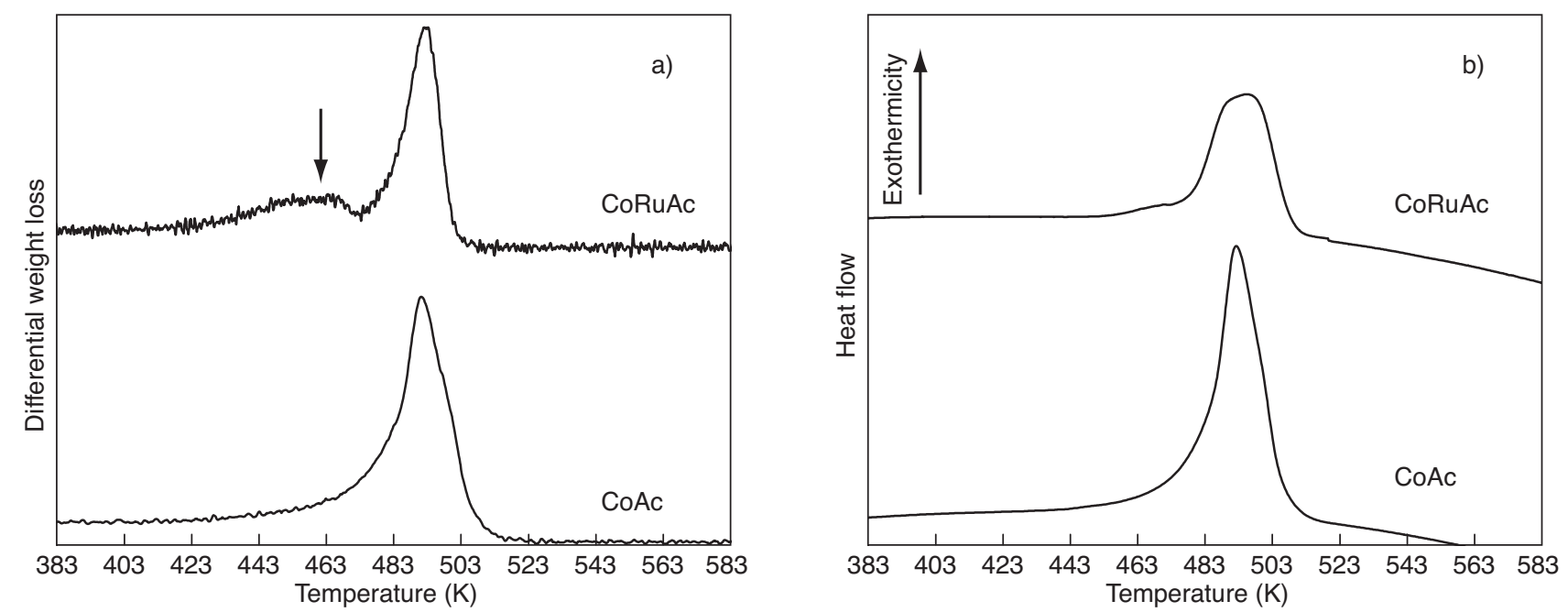

Figure 6

Differential weight loss of the impregnated monometallic and Ru-promoted cobalt silica supported catalysts prepared from cobalt acetate a); heat flow recorded during weight loss b). 


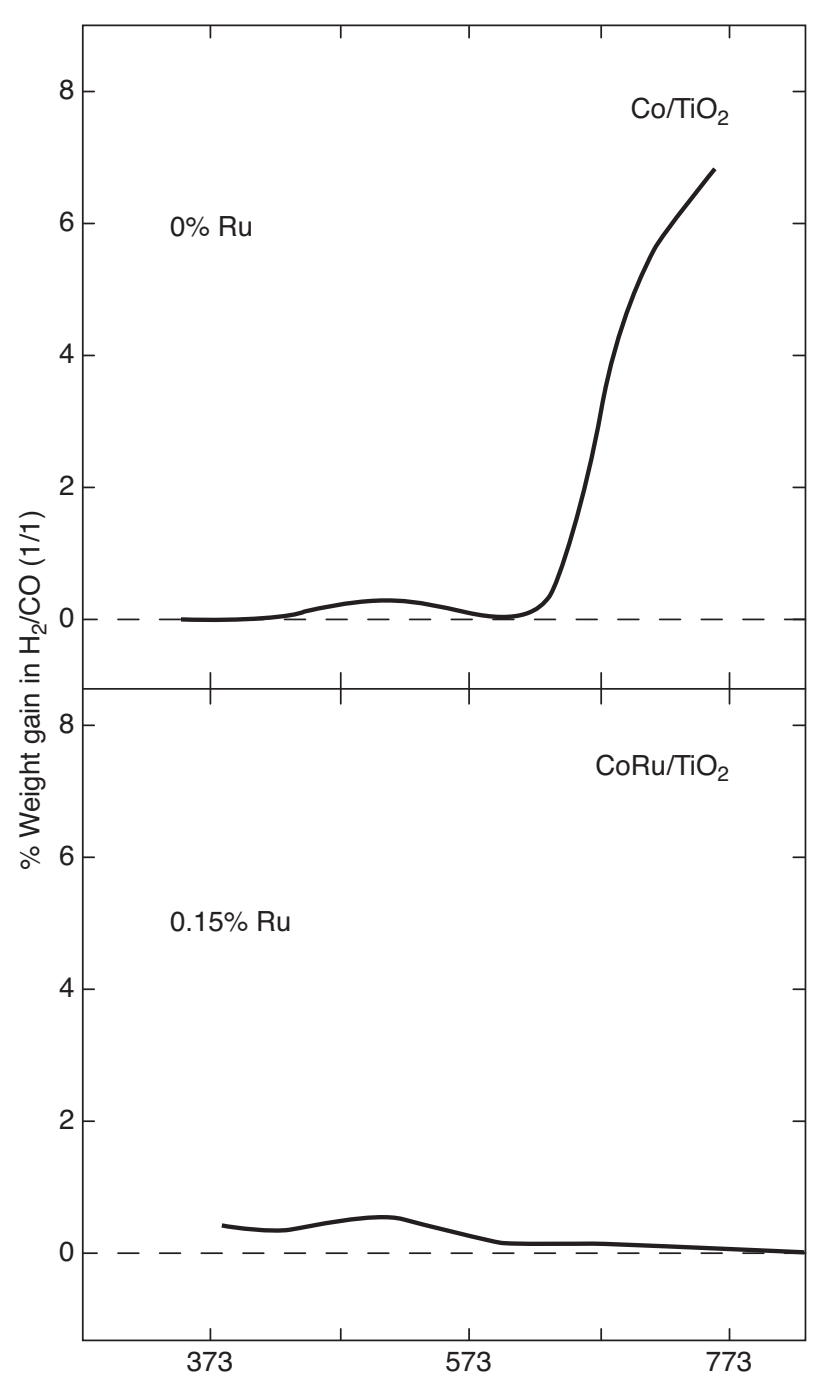

Figure 7

Effect of $\mathrm{Ru}$ on the weight gain of $\mathrm{Co} / \mathrm{TiO}_{2}$ and $\mathrm{CoRu} / \mathrm{TiO}_{2}$ catalysts in syngas $\left(\mathrm{H}_{2} / \mathrm{CO}=1\right)$ because of carburization [47].

Davis et al. [69] reported almost no changes in the rate of deactivation of $\mathrm{Co} / \mathrm{Al}_{2} \mathrm{O}_{3}$ catalysts after promotion with $\mathrm{Pt}$. Moreover, it was also shown [70] that promotion with Pt and $\mathrm{Ru}$ resulted in more unstable cobalt alumina catalysts which deactivated more rapidly in the presence of FT reaction feed and products. Holmen et al. [37] also observed more rapid deactivation of $\mathrm{CoRe} / \mathrm{Al}_{2} \mathrm{O}_{3}$ than monometallic $\mathrm{Co} / \mathrm{Al}_{2} \mathrm{O}_{3}$ catalysts.

\subsection{Hydrogen Activation}

It is known that noble metals activate hydrogen more readily than cobalt. Thus, it can be suggested that promotion with noble metals could significantly enhance hydrogen activation. More rapid hydrogen activation on cobalt FT catalysts would lead to higher reaction rate and higher fraction of saturated hydrocarbon. Guczi et al. [71, 72] suggested that in palladium promoted catalysts, palladium acted not only as a component which facilitated cobalt reduction, but it also provided additional sites for hydrogen activation.

\section{CONCLUSION}

Performance and economics, two criteria in the design of efficient cobalt Fischer-Tropsch catalysts

The available literature data suggest that promotion of cobalt catalysts with noble metals modifies both the catalyst structure and catalytic performance in FT synthesis. The most prominent effect due to the promotion is a significant increase in FT reaction rate. At low content of noble promoter (0.05-0.2 wt.\%) the hydrocarbon selectivity seems to be affected to a much lesser extent than the rate of carbon monoxide conversion. The promotion with noble metals usually results in a better cobalt reducibility and thus in a higher number of metallic cobalt sites. The ease of cobalt reduction seems to be related to more rapid hydrogen activation in the presence of noble metals and subsequent spillover of hydrogen to cobalt oxides and reduction of cobalt species. The intimate contact between cobalt and a promoter which can result in bimetallic particles does not seem to be mandatory for improving the cobalt reducibility. While the formation of bimetallic particles between cobalt and noble metal promoter is not essential in attaining high extent of cobalt reduction, it can affect the intrinsic activity of metal surface sites and thus, modify to some extent the hydrocarbon selectivity.

In many cases, the promotion with noble metals leads to a smaller average size of either cobalt oxide or cobalt metal particles. First, it has been shown that promotion with noble metal can lead to crystallization of smaller cobalt oxide particles during decomposition of cobalt precursors. This seems to be due to the presence of higher concentration of cobalt oxide nucleation and crystallization sites in the presence of noble metals. Secondly, smaller cobalt metal particles are often observed in the reduced cobalt catalysts promoted with noble metals. It is known that in monometallic cobalt catalysts, cobalt reducibility depends on the size of cobalt oxide crystallites. The presence of noble metals favors the reduction of smaller cobalt oxide particles which could not be easily reduced in monometallic cobalt catalysts in the absence of the promoters.

In the presence of noble metals, decomposition of cobalt precursors during calcination of cobalt catalysts can occur at lower temperatures. This would affect the fractions of easy and hardly reducible cobalt oxide phases in the calcined catalysts and would result in different number of cobalt metal active sites after catalyst reduction and during FT synthesis. 

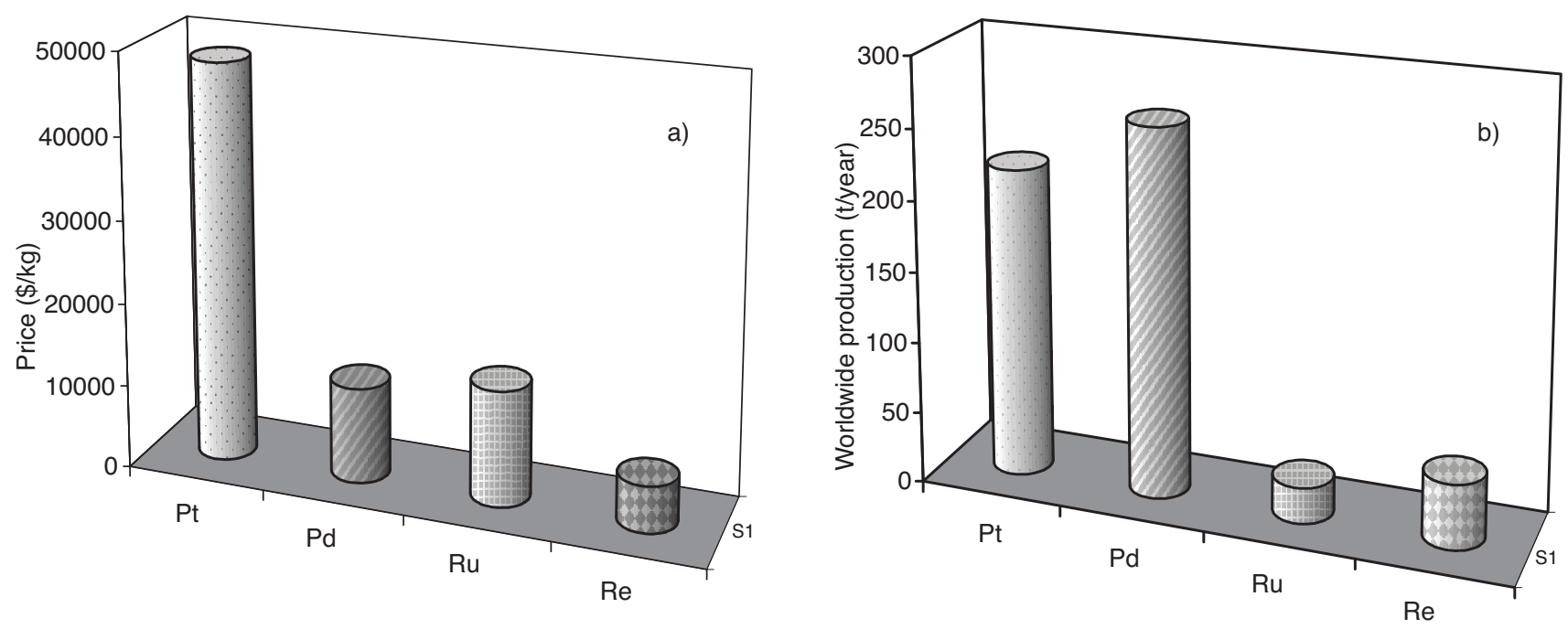

Figure 8

Prices in 2007 a) and worldwide annual production of noble metals in 2005-2006 b).

The presence of noble metal delays formation of cobaltsupport mixed compounds. The presence of noble metals affects crystallization of easy reducible cobalt oxide and hinder formation of barely reducible cobalt-support mixed compounds during catalyst calcination, catalyst reduction and FT reaction.

The data about the influence of promotion with noble metals on the deactivation of cobalt FT catalysts exhibit significant discrepancy. Because of higher hydrogenation activity of noble metals relative to cobalt, catalyst carburization can proceed more slowly during FT reaction over the catalysts containing noble metals. The presence of noble metals can also inhibit formation of cobalt-support mixed compounds at the conditions of FT synthesis. Several reports suggest however that deactivation of cobalt catalysts, which might be due to the oxidation of cobalt metal particles by water, is not much affected by the presence of noble metals. In addition, higher hydrogenation activity of noble metals, especially in the case of catalysts with a high content of noble metal promoters, can enhance hydrogen activation which would lead to higher methane selectivity, higher hydrocracking activity and lower olefin to paraffin ratio.

Both catalytic performance and catalyst cost seem to be the major criteria in the design of efficient cobalt catalysts. Because of relatively low space velocities, significant amount of cobalt FT catalyst is required for both slurry bubble column and fixed bed multi-tubular reactors. The relative prices and worldwide annual production of noble metals are shown in Figure 8. Cobalt is an expensive metal; the cobalt price was $\$ 75 / \mathrm{kg}$ in 2007 . Platinum is 650 times more expensive than cobalt. Ruthenium is 200 times expensive than cobalt.
Rhenium costs about 70 times higher than cobalt, but the market of rhenium is very volatile. Additionally, the worldwide ruthenium and rhenium resources are very limited. Promotion with noble metals could result in a major increase of the overall cost of cobalt FT catalysts (especially with Ru and $\mathrm{Re}$ ). The recycling of cobalt catalysts containing noble metal promoters seems to be mandatory [73].

A 100000 bpd GTL plant employing a 20\% cobalt supported catalyst promoted with $0.1 \%$ platinum, ruthenium, palladium or rhenium as a promoter would require $500 \mathrm{t}$ of cobalt and $2.5 \mathrm{t}$ of noble metals [74]. Manufacturing this catalyst would represent about $1 \%$ of total worldwide annual cobalt production (53 $635 \mathrm{t} /$ year in 2005 [75]) and about $1 \%$ of worldwide annual production of platinum and palladium ( 200-220 t/year for each metal). This suggests that the promotion of cobalt FT catalysts with Pt or Pd would not affect to a large extent the price of these metals. The current annual production of ruthenium is about $2 \mathrm{t}$ and that of rhenium is about $45 \mathrm{t}$. Thus, the $100000 \mathrm{bpd}$ GTL plant would require more than $5-10 \%$ of annual worldwide production of rhenium and around the whole production of $\mathrm{Ru}$. Thus, the promotion of cobalt catalysts with ruthenium and rhenium would heavily affect the worldwide market and would soar up the Ru and Re prices. Design of more active catalysts would certainly improve the overall economics of FT synthesis and whole recovery of the precious metals would be absolutely mandatory. Analysis of the dynamics of noble metal prices and market availability suggests that the promotion of cobalt FT catalysts could be only made up with platinum and palladium. Palladium is much cheaper than platinum but it has higher hydrogenation activity which limits 
production of higher hydrocarbons and waxes. Because of smaller detrimental effect on the selectivity to heavy hydrocarbons, platinum appears to be more suited for the promotion of cobalt supported FT catalysts than palladium. It should be also emphasized that promotion with noble metals is not the only possible approach to improve the performance of cobalt supported FT catalysts. Anyway, use of noble metal in the FT synthesis could offer large opportunities to help solving recurrent problems with high loading Co based catalyst for FT synthesis such as reducibility or catalyst stability. Whatever the most efficient precious metal chosen, optimization of the noble metal content should be considered as a major issue.

\section{REFERENCES}

1 Khodakov A.Y., Chu W., Fongarland P. (2007) Advances in the development of novel cobalt Fischer-Tropsch catalysts for synthesis of long-chain hydrocarbons and clean fuels, Chem. Rev. 107, 1692-1744.

2 Espinoza R.L., Steynberg A.P., Jager B., Vosloo A.C. (1999) Low temperature Fischer-Tropsch synthesis from a Sasol perspective, Appl. Catal. A-Gen. 186, 1-2, 13-26.

3 Jager B. (1998) Developments in Fischer-Tropsch technology, Stud. Surf. Sci. Catal. 119, 25-34.

4 Oukaci R., Sigleton A.H., Goodwin J.G. Jr. (1999) Comparison of patented Co F-T catalysts using fixed-bed and slurry bubble column reactors, Appl. Catal. A-Gen. 186, 129-144.

5 Iglesia E., Reyes S.C., Madon R.J., Soled S.L. (1993) Selectivity Control and Catalyst Design in the Fischer-Tropsch Synthesis: Sites, Pellets, and Reactors, Adv. Catal. 39, 221-302.

6 Iglesia E., Soled S.L., Baumgartner J.E., Reyes S.C. (1995) Synthesis and Catalytic Properties of Eggshell Cobalt Catalysts for the Fischer-Tropsch Synthesis, J. Catal. 153, 108-122.

7 Bezemer G.L., Bitter J.H., Kuipers H.P.C.E., Oosterbeek H., Holewijn J.E., Xu X., Kapteijn F., van Dillen A.J., de Jong K.P. (2006) Cobalt particle size effects in the Fischer-Tropsch reaction studied with carbon nanofiber supported catalysts, J. Am. Chem. Soc. 128, 3956-3964.

8 Barradas S., Caricato E.A., van Berge P.J., van de Loosdrecht J. (2002) Support modification of cobalt based slurry phase Fischer-Tropsch catalysts, Stud. Surf. Sci. Catal. 143, 55-65.

9 Project update: Oryx gas-to-liquids (GTL) Joint Venture, 22 May 2007, www.sasol.com/sasol_internet/frontend/navigation. jsp?articleTypeID=2\&articleId=17800001\&navid=4\&rootid $=4$.

10 Wei D., Goodwin Jr. J.G., Oukaci R., Singleton A.H. (2001) Attrition resistance of cobalt F-T catalysts for slurry bubble column reactor use, Appl. Catal. A-Gen. 210, 137-150.

11 Singleton A.H., Oukaci R., Goodwin J.G. (1999) Processes and catalysts for conducting Fischer-Tropsch synthesis in a slurry bubble column reactor, US Patent 5,939,350 assigned to Energy International Corporation.

12 Storsæter S., Borg Ø., Blekkan E.A., Holmen A. (2005) Study of the effect of water on Fischer-Tropsch synthesis over supported cobalt catalysts, J. Catal. 231, 405-419.

13 Das T.K., Jacobs G., Patterson P.M., Conner W.A., Li J., Davis B.H. (2003) Fischer-Tropsch synthesis: Characterization and catalytic properties of rhenium promoted cobalt alumina catalysts, Fuel 82, 805-815.
14 Jacobs G., Das T.K., Zhang Y., Li J., Racoillet G., Davis B.H. (2002) Fischer-Tropsch synthesis: Support, loading, and promoter effects on the reducibility of cobalt catalysts, Appl. Catal. A-Gen. 233, 263-281.

15 Schanke D., Vada S., Blekkan E.A., Hilmen A.M., Hoff A., Holmen A. (1995) Study of Pt-Promoted Cobalt CO Hydrogenation Catalysts, J. Catal. 156, 85-95; Vada S., Hoff A., Adnanes E., Schanke D., Holmen A. (1995) Top. Catal. 2, 155-162.

16 Kogelbauer A., Goodwin J.G. Jr., Oukaci R. (1996) Ruthenium promotion of $\mathrm{Co} / \mathrm{Al}_{2} \mathrm{O}_{3}$ Fischer-Tropsch catalysts, J. Catal. 160, 125-133.

17 Chu W., Chernavskii P.A., Gengembre L., Pankina G.A., Fongarland P., Khodakov A.Y. (2007) Cobalt species in promoted cobalt alumina-supported Fischer-Tropsch catalysts, $J$. Catal. 252, 215-230.

18 Tsubaki N., Sun S., Fujimoto K. (2001) Different functions of the noble metals added to cobalt catalysts for Fischer-Tropsch synthesis, J. Catal. 199, 236-246.

19 Batley G.E., Ekstrom A., Johnson D.A. (1974) Studies of topochemical heterogeneous catalysis: 3 . Catalysis of the reduction of metal oxides by hydrogen, J. Catal. 34, 368-375.

20 Takeuchi K., Matsuzaki T., Arakawa H., Hanaoka T., Sugi Y. (1989) Synthesis of C2-oxygenates from syngas over cobalt catalysts promoted by ruthenium and alkaline earths, Appl. Catal. 48, 149-157.

21 Takeuchi K., Matsuzaki T., Arakawa H., Sugi Y. (1985) Synthesis of ethanol from syngas over $\mathrm{Co}-\mathrm{Re}-\mathrm{Sr} / \mathrm{SiO}{ }_{2}$ catalysts, Appl. Catal. 18, 325-334.

22 Reinikainen M., Niemelä M.K., Kakuta N., Suhonen S. (1998) Characterisation and activity evaluation of silica supported cobalt and ruthenium catalysts, Appl. Catal A-Gen. 174, 61-75.

23 Okabe K., Li X., Wei M., Arakawa H. (2004) Fischer-Tropsch synthesis over $\mathrm{Co}-\mathrm{SiO}_{2}$ catalysts prepared by the sol-gel method, Catal. Today 89, 431-438.

24 Xu D., Li W., Duan H., Ge Q., Xu H. (2005) Reaction performance and characterization of $\mathrm{Co} / \mathrm{Al}_{2} \mathrm{O}_{3}$ Fischer-Tropsch catalysts promoted with Pt, $\mathrm{Pd}$ and $\mathrm{Ru}$, Catal. Lett. 102, 229-235.

25 Mauldin C.H., Varnado D.E. (2001) Rhenium as a promoter of titania-supported cobalt Fischer-Tropsch catalysts, Stud. Surf. Sci. Catal. 136, 417-422.

26 Martínez A., López C., Márquez F., Díaz I. (2003) FischerTropsch synthesis of hydrocarbons over mesoporous Co/SBA-15 catalysts: The influence of metal loading, cobalt precursor, and promoters, J. Catal. 220, 486-499.

27 Guczi L., Bazin D., Kovacs I., Borko L., Schay Z., Lynch J., Parent P., Lafon C., Stefler G., Koppany Z., Sajo I. (2002) Structure of $\mathrm{Pt}-\mathrm{Co} / \mathrm{Al}_{2} \mathrm{O}_{3}$ and $\mathrm{Pt}-\mathrm{Co} / \mathrm{NaY}$ bimetallic catalysts: Characterization by in situ EXAFS, TPR, XPS and by activity in Co (carbon monoxide) hydrogenation, Top. Catal. 20, 129-139.

28 Jacobs G., Das T.K., Patterson P.M., Li J., Sanchez L., Davis B.H. (2003) Fischer-Tropsch synthesis XAFS - XAFS studies of the effect of water on a Pt-promoted $\mathrm{Co} / \mathrm{Al}_{2} \mathrm{O}_{3}$ catalyst, Appl. Catal. A-Gen. 247, 335-343.

29 Qiu X., Tsubaki N., Sun S., Fujimoto K. (2002) Influence of noble metals on the performance of $\mathrm{Co} / \mathrm{SiO}_{2}$ catalyst for 1-hexene hydroformylation, Fuel 81, 1625-1630.

30 Zsoldos Z., Hoffer T., Guczi L. (1991) Structure and catalytic activity of alumina-supported Pt-Co bimetallic catalysts. 1 . Characterization by X-ray photoelectron spectroscopy, J. Phys. Chem. 95, 798-801.

31 van't Blik H.F.J., Prins R. (1986) Characterization of supported cobalt and cobalt-rhodium catalysts: III. TemperatureProgrammed Reduction (TPR), Oxidation (TPO), and EXAFS of Co-Rh/SiO ${ }_{2}$, J. Catal. 97, 210-218. 
32 Castner D.G., Watson P.R., Chan I.Y. (1990) X-ray absorption spectroscopy, X-ray photoelectron spectroscopy, and analytical electron microscopy studies of cobalt catalysts. 2. Hydrogen reduction properties, J. Phys. Chem. 94, 819-828.

33 Ernst B., Bensaddik A., Hilaire L., Chaumette P., Kiennemann A. (1998) Study on a cobalt silica catalyst during reduction and Fischer-Tropsch reaction: In situ EXAFS compared to XPS and XRD, Catal. Today 39, 329-341.

34 Bechara R., Balloy D., Dauphin J.-Y., Grimblot J. (1999) Influence of the characteristics of $\gamma$-aluminas on the dispersion and the reducibility of supported cobalt catalysts, Chem. Mater. 11, 1703-1711.

35 Khodakov A.Y, Lynch J., Bazin D., Rebours B., Zanier N., Moisson B., Chaumette P. (1997) Reducibility of cobalt species in silica-supported Fischer-Tropsch catalysts, J. Catal. 168, 1625.

36 Hilmen A.M., Schanke D., Holmen A. (1996) TPR study of the mechanism of rhenium promotion of alumina-supported cobalt Fischer-Tropsch catalysts, Catal. Lett. 38, 143-147.

37 Hilmen A.M., Schanke D., Hanssen K.F., Holmen A. (1999). Study of the effect of water on alumina supported cobalt FischerTropsch catalysts, Appl. Catal. A-Gen. 186, 169-188.

38 Jacobs G., Chaney J.A., Patterson P.M., Das T.K., Davis B.H. (2004) Fischer-Tropsch synthesis: Study of the promotion of Re on the reduction property of $\mathrm{Co} / \mathrm{Al}_{2} \mathrm{O}_{3}$ catalysts by in situ EXAFS/XANES of Co K and Re LIII edges and XPS, Appl. Catal. A-Gen. 264, 203-212.

39 Shannon M.D., Lok C.M., Casci J.L. (2007) Imaging promoter atoms in Fischer-Tropsch cobalt catalysts by aberration-corrected scanning transmission electron microscopy, J. Catal. 249, 41-51.

40 Jacobs G., Ji Y., Davis B.H., Cronauer D., Kropf A.J., Marshall C.L. (2007) Fischer-Tropsch synthesis: Temperature programmed EXAFS/XANES investigation of the influence of support type, cobalt loading, and noble metal promoter addition to the reduction behavior of cobalt oxide particles, Appl. Catal. AGen. 333, 177-191.

41 Bertole C.J., Mims C.A., Kiss G. (2004) Support and rhenium effects on the intrinsic site activity and methane selectivity of cobalt Fischer-Tropsch catalysts, J. Catal. 221, 191-203.

42 Bertole C.J., Mims C.A., Kiss G., Joshi P. (2001) Site reactivity of Fischer-Tropsch synthesis catalysts studied by ${ }^{12} \mathrm{CO} \rightarrow{ }^{13} \mathrm{CO}$ isotope transients, Stud. Surf. Sci. Catal. 136, 369-374.

43 Vada S., Hoff A., Ådnanes E., Schanke D., Holmen A. (1995) Fischer-Tropsch synthesis on supported cobalt catalysts promoted by platinum and rhenium, Top. Catal. 2, 155-162.

44 Jacobs G., Chaney J.A., Patterson P.M., Das T.K., Maillot J.C., Davis B.H. (2004) Fischer-Tropsch synthesis: Study of the promotion of $\mathrm{Pt}$ on the reduction property of $\mathrm{Co} / \mathrm{Al}_{2} \mathrm{O}_{3}$ catalysts by in situ EXAFS of $\mathrm{Co} \mathrm{K}$ and $\mathrm{Pt}_{\mathrm{L}}$ III edges and XPS, J. Synchrotron Radiat. 11, 414-422.

45 Girardon J.-S., Quinet E., Griboval-Constant A., Chernavskii P.A., Gengembre L., Khodakov A.Y. (2007) Cobalt dispersion, reducibility, and surface sites in promoted silica-supported Fischer-Tropsch catalysts, J. Catal. 248, 143-157.

46 Chernavskii P.A., Khodakov A.Y., Pankina G.V., Girardon J.-S., Quinet E. (2006) In situ characterization of the genesis of cobalt metal particles in silica-supported Fischer-Tropsch catalysts using Foner magnetic method, Appl. Catal. A-Gen. 306, 108119.

47 Iglesia E., Soled S.L., Fiato R.A., Via G.H. (1993) Bimetallic synergy in cobalt ruthenium Fischer-Tropsch synthesis catalysts, J. Catal. 143, 345-368.
48 Carlsson A.F., Naschitzki M., Bäumer M., Freund H.-J. (2003) The structure and reactivity of $\mathrm{Al}_{2} \mathrm{O}_{3}$-supported cobalt-palladium particles: A CO-TPD, STM, and XPS study, J. Phys. Chem. B 107, 778-785.

49 Bardi U., Beard B.C., Roos P.N. (1990) CO chemisorption on the [111] and [100] oriented single crystal surfaces of the alloy $\mathrm{CoPt}_{3}$, J. Catal. 124, 22-29.

50 Bazin D., Guczi L. (2004) A review of in situ XAS study on Cobased bimetallic catalysts relevant to CO hydrogenation, Stud. Surf. Sci. Catal. 147, 343-348.

51 Guczi L., Bazin D. (1999) Structure and selectivity of metal catalysts: Revisiting bimetallic zeolite systems, Appl. Catal. A-Gen . 188, 163-174.

52 Rønning M., Nicholson D.G., Holmen A. (2001) In situ EXAFS study of the bimetallic interaction in a rhenium-promoted alumina-supported cobalt Fischer-Tropsch catalyst, Catal. Lett. 72, 141-146.

53 Guczi L. (2005) Bimetallic nano-particles: Featuring structure and reactivity, Catal. Today 101, 53-64.

54 Noronha F.B., Schmal M., Moraweck B., Delichère P., Brun M., Villain F., Fréty R (2000) Characterization of niobia-supported palladium - Cobalt catalysts, J. Phys. Chem. B 104, 5478-5485.

55 Dees M.J., Ponec V. (1989) The influence of sulfur and carbonaceous deposits on the selectivity and activity of $\mathrm{Pt} / \mathrm{Co}$ catalysts in hydrocarbon reactions, J. Catal. 119, 376-387.

56 Sun S., Fujimoto K., Yoneyama Y., Tsubaki N. (2002) FischerTropsch synthesis using $\mathrm{Co} / \mathrm{SiO}_{2}$ catalysts prepared from mixed precursors and addition effect of noble metals, Fuel 81, 15831591.

57 Storsæter S., Tøtdal B., Walmsley J.C., Tanem B.S., Holmen A. (2005) Characterization of alumina-, silica-, and titania-supported cobalt Fischer-Tropsch catalysts, J. Catal. 236, 139-152.

58 Li P., Liu J., Nag N., Crozier P.A. (2006) In situ synthesis and characterization of $\mathrm{Ru}$ promoted $\mathrm{Co} / \mathrm{Al}_{2} \mathrm{O}_{3}$ Fischer-Tropsch catalysts, Appl. Catal. A-Gen. 307, 212-221.

59 Nowitzki T., Carlsson A.F., Martyanov O., Naschitzki M., Zielasek V., Risse T., Schmal M., Freund H.-J., Bäumer M. (2007) Oxidation of alumina-supported Co and Co-Pd model catalysts for the Fischer-Tropsch reaction, J. Phys. Chem. C 111, 8566-8572.

60 Hong J., Chernavskii P.A., Khodakov A.Y., Chu W. (2008) Effect of promotion with ruthenium on the structure and catalytic performance of meso-porous silica (smaller and larger pore) supported cobalt Fischer-Tropsch catalysts, Catal. Today, in press.

61 Chaung T.J., Brundle C.R., Rice D.W. (1976) Interpretation of the X-ray photoemission spectra of cobalt oxides and cobalt oxide surfaces, Surf. Sci. 59, 413-429.

62 Ho S.W., Horialla M., Hercules D.M. (1990) Effect of particle size on CO hydrogenation activity of silica supported cobalt catalysts, J. Phys. Chem. 94, 6396-6399.

63 Bonnelle J.P., Grimblot. J., D’huysser A. (1975) Influence de la polarisation des liaisons sur les spectres esca des oxydes de cobalt, J. Electron Spectrosc. 7, 151-162.

64 Castner D.G., Watson P.R., Chan I.Y. (1989) X-ray absorption spectroscopy, X-ray photoelectron spectroscopy, and analytical electron microscopy studies of cobalt catalysts. 1. Characterization of calcined catalysts, J. Phys. Chem. 93, 31883194.

65 Jongsomjit B., Panpranot J., Goodwin Jr. J.G. (2001) Co-support compound formation in alumina-supported cobalt catalysts, $J$. Catal. 204, 98-109. 
66 Girardon J.-S., Constant-Griboval A., Gengembre L., Chernavskii P.A., Khodakov A.Y. (2005) Optimization of the pretreatment procedure in the design of cobalt silica supported Fischer-Tropsch catalysts, Catal. Today 106, 161-165.

67 Guczi L., Stefler G., Koppány Z., Borkó L. (2001) CO hydrogenation over Re-Co bimetallic catalysts supported over $\mathrm{SiO}_{2}$, $\mathrm{Al}_{2} \mathrm{O}_{3}$ and $\mathrm{NaY}$ zeolite, React. Kinet. Catal. L. 74, 259-269.

68 Guczi L., Stefler G., Borkó L., Koppány Zs., Mizukami F., Toba M., Niwa S. (2003) Re-Co bimetallic catalysts prepared by $\mathrm{sol} / \mathrm{gel}$ technique: Characterization and catalytic properties, Appl. Catal. A-Gen. 246, 79-86.

69 Das T.K., Jacobs G., Davis B.H. (2005) Fischer-Tropsch synthesis: Deactivation of promoted and unpromoted cobalt-alumina catalysts, Catal. Lett. 101, 187-190.

70 Jacobs G., Patterson P.M., Zhang Y., Das T., Li J., Davis B.H. (2002) Fischer-Tropsch synthesis: Deactivation of noble metalpromoted $\mathrm{Co} / \mathrm{Al}_{2} \mathrm{O}_{3}$ catalysts, Appl. Catal. A-Gen. 233, 215-226.
71 Guczi L., Borkó L., Schay Z., Bazin D., Mizukami F. (2001) CO hydrogenation and methane activation over $\mathrm{Pd}-\mathrm{Co} / \mathrm{SiO}_{2}$ catalysts prepared by sol/gel method, Catal. Today $\mathbf{6 5}, 51-57$.

72 Guczi L., Schay Z., Stefler G., Mizukami F. (1999) Bimetallic catalysis: $\mathrm{CO}$ hydrogenation over palladium-cobalt catalysts prepared by sol/gel method, J. Mol. Catal. A-Chem. 141, 177-185.

73 Matjie R.H., Scurrell M.S., Bunt J. (2005) The selective dissolution of alumina, cobalt and platinum from a calcined spent catalyst using different lixiviants, Miner. Eng. 18, 801-810.

74 Brumby A., Verhelst M., Cheret D. (2005) Recycling GTL catalysts - A new challenge, Catal. Today 106, 166-169.

75 Kapusta J.P.T. (2006) Cobalt production and markets: A brief overview, JOM 58, 33-36.

Final manuscript received in May 2008 Published online in October 2008 or distributed for profit or commercial advantage and that copies bear this notice and the full citation on the first page. Copyrights for components of this work owned by others than IFP must be honored. Abstracting with credit is permitted. To copy otherwise, to republish, to post on servers, or to redistribute to lists, requires prior specific permission and/or a fee: Request permission from Documentation, Institut français du pétrole, fax. +33147527078 , or revueogst@ifp.fr. 